\title{
An Assessment of Association between Neighborhood Socioeconomic Status and Infant Mortality in High Focus States in India
}

\author{
Ashish Kumar Gupta ${ }^{*}$, Laishram Ladusingh ${ }^{2}$ \\ ${ }^{1}$ Povert, Gender and Youth (PGY), Population Council, New Delhi, India \\ ${ }^{2}$ Department of Mathematical Demography \& Statistics, IIPS, Mumbai, India \\ Email: "ashishatbhu@gmail.com, Islaishram@iips.net
}

Received 24 March 2016; accepted 8 May 2016; published 11 May 2016

Copyright (C) 2016 by authors and Scientific Research Publishing Inc.

This work is licensed under the Creative Commons Attribution International License (CC BY). http://creativecommons.org/licenses/by/4.0/

\begin{abstract}
Neighbourhood characteristics influence infant mortality above and beyond individual/household factors. In India, there are very few studies discussing the effects of neighbourhood characteristics on infant mortality. This study examined the effect of neighbourhood socioeconomic characteristics on infant mortality using data from the India's Third District Level Household Survey conducted in 2007-2008. Multilevel analyses applied on the representative sample of 168,625 nested within 14,193 communities using MCMC procedure. Results established that place of residence, neighbourhood socio-economic factors as important determinants of infant mortality. Overall, being born in affluent (OR: 0.79, p < 0.01), more educated (OR: $0.86, p<0.01$ ) and socially disadvantaged caste (OR: $0.83, p<0.01$ ) neighbourhood was associated with the significant reduction in hazards of infant death. The finding of this study suggests that effort should be made to reduce infant mortality in these high focus states by including policies which aim at improving infant survival in the neighbourhood that is economically and socially deprived.
\end{abstract}

\section{Keywords}

Neighborhood Effect, High Focus States, Infant Mortality Rate, Multilevel Analysis

\section{Introduction}

Infant and child mortality in India has declined from 80 deaths per thousand live births in the 1990's to 40 in "Corresponding author.

How to cite this paper: Gupta, A.K. and Ladusingh, L. (2016) An Assessment of Association between Neighborhood Socioeconomic Status and Infant Mortality in High Focus States in India. Health, 8, 630-641. 
2013 [1]. Though the progress is significant, the pace of decline in infant and child mortality is not adequate and has resulted in missing the Millennium Development Goal-IV in respect of infant and child mortality [2] along with other developing countries. India's lackluster performance has received considerable scholarly attention during the past decades. Besides the slow pace of decline, there is notable regional variation in the patterns and clustering of infant and child mortality across the regions/country [3]-[5]. One plausible explanation for the unsatisfactory decline of Infant Mortality Rate (IMR) may be related to disparities in health, contextual factors and social conditions across state/districts/communities [6]. Empirical examination of trend and pattern of IMR across the states reveals that, there are a few states with unacceptably high fertility and mortality indicators. These states, appropriately designated as "high-focus" states by the government of India, comprise Uttar Pradesh, Uttarakhand, Bihar, Jharkhand, Chhattisgarh, Odisha, Madhya Pradesh, Rajasthan and Assam covers large part of the India. To place the subject in perspective, these states account for 284 of India's 676 districts (Census 2011) and 48.5 percent its population [7]. India embarked on its very ambitious health programme- the National Rural Health Mission (NRHM) - in 2005, to overcome the health infrastructure hurdles in rural areas. Although the progress under this programme has been significant in improving the overall health status of children, the improvement is not uniform across the subgroups of population [8].

A matter of even bigger concern is that, according to Sample Registration System (SRS-2013) [1], the four states of Madhya Pradesh (MP), Assam (AS), Uttar Pradesh (UP) and Odisha (OD) have infant mortality rates of above 50 per 1000 live births, the highest in the country. Published studies provide evidence that, disparities in child health outcomes may arise from differences in the characteristics of the families that children are born into as well as differences in the socioeconomic attributes of the communities in which they live [9]-[12]. However, the literature also shows that knowledge about the determinants of childhood mortality at the individual level is insufficient to address the problem [9] [12]. This is because the contextual characteristics of the community or neighborhood where children are born or raised tend to modify child-level and mother-level characteristics and, therefore, affect the chances of survival for children [13]. This has propelled researchers to include the neighborhood/community effect prominently in analytical and theoretical models of infant and child survival [14] [15].

Social scientists and medical geographers have long acknowledged neighborhood/community as an important determinant of health outcome disparities. Nonetheless, scholars across the globe have mainly focused on the importance of individual factors on child health. However, there is increasing support for the hypothesis that infant and child death risks are associated with particular social structures and community ecologies, which can provide useful feedback to policy makers for the development of public health interventions [9] [10] [16]-[20]. Existing studies have generally focused on assessment of community effect on health outcomes by using community-level variables using different kind of the data, definitions, and methods [21] [22]. Despite that, supporting evidences are sparse, thereby underscoring the necessity to understand the importance of neighborhood contexts for individuals' health outcomes.

Therefore, this study is an effort to contribute to the global discourse on the differential health outcomes among communities by integrating the effects of neighborhood contexts as risk factors for infant mortality. To the author's knowledge, there are very few studies that systematically computed neighborhood socioeconomic variables by excluding index women household using unit level information about individual socioeconomic condition.

Against the backdrop of existing studies and the current debate about uneven decline of IMR across the states, a few questions are pertinent to the issue and must be raised:

- Whether maternal- and child-level factors are enough to explain regional disparities in IMR?

- Whether areas, which are surrounded by less affluent and low educational attainment having a higher proportion of socially disadvantaged group (SC/ST), have a higher risk of infant death?

- Whether focus on neighborhood-level factors would be more appropriate for programmatic intervention?

The objective of this paper is to address some of these questions by examining the neighborhood effect on IMR in the high-focus states of India after adjusting for individual-level factors. Such a consideration is particularly important from the point of view of the fact that even in the high-focus states, there exist wide inter- and intra-state variations.

To this end, this study aims to 1) examine the effects of individual- and neighborhood-level characteristics on child survival during infancy and 2) determine the extent to which characteristics at the individual- and community-levels explain variations in infant mortality in the high-focus states. More importantly, this study adds to the body of literature by investigating effect of neighborhood socioeconomic factors such as education, higher proportion of socially disadvantaged groups (SCs/STs) and economic status on infant mortality after adjusting the effect of maternal/child level confounders. 


\subsection{Theoretical Background}

During the past three decades, a number of studies have examined the impact of socioeconomic status (SES) and SES-related factors on infant and overall mortality [23] [24]. Yet, the mechanisms linking SES to mortality are not clear. It has been documented in several researches that individuals who live in poorer and more disadvantaged neighborhoods have inferior health outcomes [11] [16]. Several reviews of studies using multilevel analysis have concluded that neighborhood socioeconomic status (SES) has an independent effect on a wide variety of individual health outcomes even when controlling for individual SES and other individual characteristics [11] [16].

The field of "neighborhood effects research" is concerned with empirically demonstrating the existence of these types of contextual influences on health. It is a growing area of study with contributions from diverse disciplines ranging from demography, social epidemiology, geography, medical sociology, and economics [25]. In the context of documented research relating neighborhood socioeconomic position and infant and child mortality, Sastry [12] argued that neighborhood characteristics can aggravate or alleviate mortality risks of individuals depending on the neighborhood contexts where individuals reside. Further, recent evidences have continued to underscore the importance of neighborhood characteristics on health outcomes [26]-[28]. Considering the significant decrease in infant and overall mortality, the role of neighborhood effect on mortality cannot be ignored. There is increasing support to the hypothesis that individual deprivation combined with prosperous neighborhood positively affects the health. Keeping in view the findings reported in earlier literature that indicate growing interest in the study of the effects of community or the neighborhood context on health outcomes in developing countries, this paper seeks to increase the understanding of the extent to which characteristics at individual and community levels influence variations in infant mortality for impoverished states of India.

\section{Data and Methods}

\subsection{Data}

Data from the third District Level Household Survey (DLHS-3, IIPS-2010) [29] were analyzed for this study. The definition of neighborhood that has been adopted is simply, the "neighborhood area" consists of a group of home areas that share a commonly defined residential area that often has a name. In some studies, geographical boundaries, developed for census or other political purpose, as proxies of actual communities or neighborhood (Roberts, 1997). In this study geographical boundaries defined by Census-2001 which has been further adopted by DLHS-3 considered as neighborhood (community). In DLHS-3, PSUs are either a village or part of it in rural areas and a census enumeration block (CEB) in urban areas.

The outcome variable for this study of survival status of child in the first year of life, coded as 1 for death and 0 for alive. The independent variables in this paper included important characteristics at the individual, familial and neighborhood levels. The variables at individual level include characteristics at child and mother levels. Selected neighborhood level variables in this study include: Neighborhood mean wealth index, Neighborhood mean level of education and Proportion of socially disadvantaged groups (SC/ST) at PSU level. These neighborhood level variables have been assorted or aggregated to PSU-level from individual- and household-level excluding index women's household.

\subsection{Methods}

Two-level random intercept logistic regression (with the outcome being infant death within a neighborhood) was used to estimate the effect of the neighborhood (PSU) level variable after taking into account potential sociodemographic confounders at the individual and household levels. The multilevel regression coefficients were estimated using Markov Chain Monte Carlo (MCMC) estimation procedures by runmlwin, stata module for fitting multilevel models in the MLwiN software package [30].

\section{Results}

The distribution of the study sample by individual-level characteristics is presented in Table 1 . To arrive at a model which best fits the present study, we fitted five versions of the multilevel model described in the preceding section. Model-I is an empty model without any covariates; in Model-II, state dummy variables are incorporated; and model-III is designed to explore the effect of individual and maternal characteristics on risk of infant 
Table 1. Percentage distribution of child/mother level characteristic for the high focus states of India, 2007-2008.

\begin{tabular}{|c|c|}
\hline Variable/category & High focus states \% (n) \\
\hline \multicolumn{2}{|l|}{ Child's sex } \\
\hline Male & $52.00(87693)$ \\
\hline Female & 48.00 (80932) \\
\hline \multicolumn{2}{|l|}{ Birth order } \\
\hline 1 & $29.70(50082)$ \\
\hline 2 & $23.82(40171)$ \\
\hline 3 & 16.75 (28245) \\
\hline $4+$ & 29.73 (50127) \\
\hline \multicolumn{2}{|l|}{ Mother's age } \\
\hline$<20$ & $14.10(23776)$ \\
\hline $20-34$ & 79.20 (133551) \\
\hline $35+$ & $6.70(11298)$ \\
\hline \multicolumn{2}{|l|}{ Maternal education } \\
\hline No education & 58.55 (98729) \\
\hline Primary & $14.01(23627)$ \\
\hline Middle and high school & 21.14 (35650) \\
\hline Higher secondary & 3.34 (5629) \\
\hline Graduation and above & $2.96(4990)$ \\
\hline \multicolumn{2}{|l|}{ Wealth index } \\
\hline Poorest & 28.60 (48227) \\
\hline Poorer & $26.70(45023)$ \\
\hline Middle & 19.10 (32207) \\
\hline Richer & $15.10(25462)$ \\
\hline Richest & $10.50(17706)$ \\
\hline \multicolumn{2}{|l|}{ Caste } \\
\hline Other caste & 14.20 (31045) \\
\hline Scheduled caste/scheduled tribe & 33.53 (56233) \\
\hline Other backward caste & 46.40 (78351) \\
\hline Missing caste & $1.6(2696)$ \\
\hline \multicolumn{2}{|l|}{ Place of delivery } \\
\hline Home & $31.50(53100)$ \\
\hline Health facility & $68.50(115525)$ \\
\hline \multicolumn{2}{|l|}{ Pre-natal care } \\
\hline At least 4 ANC & 12.80 (21493) \\
\hline less than 4 ANC & 87.25 (147132) \\
\hline \multicolumn{2}{|l|}{ Place of residence } \\
\hline Rural & $87.00(146698)$ \\
\hline Urban & 13.00 (21927) \\
\hline
\end{tabular}


death. In model-IV, neighboring households' wealth Index, proportion of socially disadvantaged group (SC/ST) and mean level of education in the community excluding the index woman's household is introduced. In Model$\mathrm{V}$, individual-level characteristics along with neighborhood backgrounds are modeled.

Multilevel analyses applied on the representative sample of 168,625 nested within 14,193 communities using MCMC procedure the results of the null model (Model-I) showed a significant variation in infant mortality (Table 2) at child/mother- and neighborhood-levels. The significant variation thus justifies the use of multilevel modeling in this study. The results from analysis indicated that the inter community variance (expressed as VPC or ICC) in infant mortality was $6 \%$ in state level model. The estimated PCV (percentage change in variation) shows $39.5 \%$, and the $15.2 \%$ variance associated with infant mortality across individual- and community-levels is explained by state in which an infant is born or raised. Adding the state as covariate in Model-II, introducing mother and child-level variables into Model-III also yielded significant variance across communities. For instance, as indicated by the proportional change in variance (PCV) in Model-III in Table 2, 11.86 and 17.39 of the variance in the risks of infant mortality across individual and community levels respectively were attributed to child and mother level variables. Variances that resulted from inclusion of only community-level characteristics in the multilevel modeling were significant (Model-IV). As indicated by the PCV in Model-IV (Table 2), 11.86\% and $19.57 \%$ respectively of the variance in the risks of death during infancy across individual- and communitylevel could be explained by characteristics at the neighborhood level. The last model (Model-V), which includes all the variables, suggests significant variation in the risk of infant death at community- as well as individual-level. The fixed part of the model (Table 3) suggest that infants born to women residing in Uttar Pradesh (OR: 4.15, $\mathrm{p}<0.01$ ), Chhattisgarh (OR: 3.63, $\mathrm{p}<0.01$ ), Bihar (OR: 2.92, $\mathrm{p}<0.01$ ), Rajasthan (OR: 2.79, $\mathrm{p}<0.01$ ), Assam (OR: 2.64, p < 0.01), Madhya Pradesh (OR: 2.60, p < 0.01), Odisha (OR: 2.30, p < 0.01) and Jharkhand (OR: 1.96, $\mathrm{p}<0.01$ ) had significantly higher odds of infant death as compared with children in Uttarakhand.

After including other socioeconomic, demographic and neighborhood variable as covariates in the subsequent models, the risk of infant death was attenuated for all the states. The measures of variation in Model II to Model $\mathrm{V}$ show that, inclusion of the states as dummy covariate yield a significant variance across individual and neighborhood level (Table 2) The results from Model V (Table 2) indicate that neighborhood socioeconomic status is significantly associated with risk of infant death. Results established (Table 3) that place of residence; maternal education, mother's age, neighborhood and community socio-economic contexts are important determinants of infant mortality in India. Results indicate that being born or raised in an affluent (OR: $0.79, \mathrm{p}<0.01$ ), more educated (OR: $0.86 \mathrm{p}<0.01$ ) neighborhood was associated with significant reduction in risk of death in infancy. In addition, caste segregation in the context of high proportion of socially disadvantaged group (SC/ST) in the community also adversely affects the chances of infant survival. Finally, the decreasing values of DIC (Deviance information criterion) with each successive model indicated a good fit of the multilevel models, thus signifying a significant improvement over the previous model.

In Figure 1, five-way MCMC graphical diagnostic plot have been generated to see the convergence and autocorrelation in the model. On the first row, the left panel plots the trace of the chain while the right panel plots a smoothed histogram of the chain. On the second row, the left panel is an auto-correlation function (ACF) plot

Table 2. Parameter coefficients for the multilevel model (random intercept only model, without covariates) for various indicators of the infant death, high focus states in India, DLHS-3 (2007-2008).

\begin{tabular}{cccccc}
\hline Random effects & $\begin{array}{c}\text { Empty model } \\
\text { (Model-I) }\end{array}$ & $\begin{array}{c}\text { State level } \\
\text { (Model-II) }\end{array}$ & $\begin{array}{c}\text { Child and mother level } \\
\text { (Model-III) }\end{array}$ & $\begin{array}{c}\text { Neighborhood level characteristic } \\
\text { (Model-IV) }\end{array}$ & $\begin{array}{c}\text { Full model } \\
\text { (Model-V) }\end{array}$ \\
\hline Variance (SE) & $0.46(0.025)$ & $0.39(0.026)$ & $0.38(0.04)$ & $0.37(0.06)$ & $0.36(0.02)$ \\
VPC (\%) & 12.21 & 10.74 & 12.07 & 10.15 & 10.02 \\
Explained variation & ref & 15.22 & 17.39 & 19.57 & 21.73 \\
$\begin{array}{c}\text { (i.e. PCV in \%) } \\
\text { Variance (SE) }\end{array}$ & $0.04(0.001)$ & $0.06(0.001)$ & $0.09(0.004)$ & $0.09(0.03)$ & $0.17(0.02)$ \\
Explained variation & ref & 39.53 & 11.86 & 11.86 & 29.5 \\
(i.e. PCV in \%) & & & & & 63773.40 \\
\hline DIC & 66390.45 & 65986.36 & 64159.30 & 65831.10 & 6 \\
\hline
\end{tabular}

Notes: PSU = Primary Sampling Unit; SE = Standard Error; VPC = Variance Partition Coefficient. 
Table 3. Child and mother-level compositional and neighborhood contextual factors associated with infant mortality in high focus states of India, DLHS-III, 2007-2008.

\begin{tabular}{|c|c|c|c|c|c|}
\hline Characteristics & Model I & Model II & Model III & Model IV & Model V \\
\hline Fixed effects & Empty model & State & Child and mother level & Neighborhood level characteristic & Full model \\
\hline \multicolumn{6}{|c|}{ State } \\
\hline Uttarakhand & & 1 & 1 & 1 & \\
\hline Rajasthan & & $2.79^{* * *}$ & $2.27^{* * *}$ & $2.36^{* * *}$ & $2.06^{* * *}$ \\
\hline Uttar Pradesh & & $4.15^{* * *}$ & $3.61^{* * *}$ & $3.63^{* * *}$ & $3.30^{* * *}$ \\
\hline Bihar & & $2.92^{* * *}$ & $2.40^{* * *}$ & $2.35^{* * *}$ & $2.05^{* * *}$ \\
\hline Assam & & $2.64^{* * *}$ & $2.57^{* * *}$ & $2.33^{* * *}$ & $2.19^{* * *}$ \\
\hline Jharkhand & & $1.96^{* * *}$ & $1.70^{* * *}$ & $1.53^{* * *}$ & $1.34^{* * *}$ \\
\hline Orrisa & & $2.30^{* * *}$ & $2.08^{* * *}$ & $1.87^{* * *}$ & $1.70^{* *}$ \\
\hline Chattisgarh & & $3.63^{* * *}$ & $3.28^{* * *}$ & $2.92^{* * *}$ & $2.61^{* * *}$ \\
\hline Madhya Pradesh & & $2.60^{* * *}$ & $2.17^{* * *}$ & $2.15^{* * *}$ & $1.62^{* * *}$ \\
\hline \multicolumn{6}{|c|}{ Child's sex } \\
\hline Male & & & 1 & & 1 \\
\hline Female & & & $0.93^{* * *}$ & & 0.93 \\
\hline \multicolumn{6}{|c|}{ Birth order } \\
\hline 1 & & & 1 & & 1 \\
\hline 2 & & & 0.81 & & $0.81^{* * *}$ \\
\hline 3 & & & 0.76 & & $0.82^{* * *}$ \\
\hline $4+$ & & & 0.87 & & $0.87^{* * *}$ \\
\hline \multicolumn{6}{|c|}{ Mother'age } \\
\hline$<20$ & & & 1 & & 1 \\
\hline $20-34$ & & & $0.70^{* * *}$ & & $0.65^{* * *}$ \\
\hline $35+$ & & & $0.83^{* * *}$ & & $0.77^{* * *}$ \\
\hline \multicolumn{6}{|c|}{ Maternal education } \\
\hline No education & & & 1 & & \\
\hline Primary & & & $0.89^{* * *}$ & & 0.96 \\
\hline $\begin{array}{l}\text { Middle and high } \\
\text { school }\end{array}$ & & & $0.73^{* * *}$ & & $0.82^{* * *}$ \\
\hline Higher secondary & & & $0.56^{* * *}$ & & $0.65^{* * *}$ \\
\hline $\begin{array}{l}\text { Graduation and } \\
\text { above }\end{array}$ & & & $0.45^{* * *}$ & & $0.54^{* * *}$ \\
\hline \multicolumn{6}{|c|}{ Wealth index } \\
\hline Poorest & & & 1 & & 1 \\
\hline Poorer & & & $0.92^{* * *}$ & & $0.93^{* * *}$ \\
\hline Middle & & & $0.85^{* * *}$ & & $0.83^{* * *}$ \\
\hline Richer & & & $0.86^{* * *}$ & & $0.83^{* * *}$ \\
\hline Richest & & & $0.69^{* * *}$ & & $0.63^{* * *}$ \\
\hline \multicolumn{6}{|c|}{ Caste } \\
\hline Other caste & & & 1 & & 1 \\
\hline
\end{tabular}




\begin{tabular}{|c|c|c|c|}
\hline Continued & & & \\
\hline $\begin{array}{c}\text { Scheduled } \\
\text { caste/scheduled } \\
\text { tribe }\end{array}$ & $1.14^{* * *}$ & & $1.18^{* * *}$ \\
\hline $\begin{array}{l}\text { Other backward } \\
\text { caste }\end{array}$ & $1.07^{* * *}$ & & $1.05^{* * *}$ \\
\hline \multicolumn{4}{|l|}{ Place of delivery } \\
\hline Home & 1 & & 1 \\
\hline Health facility & $0.90^{* * *}$ & & $0.81^{* * *}$ \\
\hline \multicolumn{4}{|l|}{$\begin{array}{l}\text { Had pre-natal } \\
\text { care }\end{array}$} \\
\hline Yes & 1 & & 1 \\
\hline No & $0.92^{* * *}$ & & $0.95^{* *}$ \\
\hline \multicolumn{4}{|l|}{ Place of residence } \\
\hline Rural & 1 & & 1 \\
\hline Urban & $0.90^{* * *}$ & $0.88^{* * *}$ & 0.98 \\
\hline \multicolumn{4}{|c|}{ Neighborhood maternal level of education } \\
\hline Low & & & 1 \\
\hline Medium & & $0.91^{* * *}$ & 0.97 \\
\hline High & & $0.86^{* *}$ & 0.95 \\
\hline \multicolumn{4}{|c|}{ Neighborhood mean wealth Index } \\
\hline Poorest & & 1 & 1 \\
\hline Poorer & & $0.89^{* * *}$ & $0.91^{* * *}$ \\
\hline Middle & & $0.83^{* * *}$ & $0.86^{* * *}$ \\
\hline Rich & & $0.79^{* * *}$ & $0.86^{* * *}$ \\
\hline $\begin{array}{l}\text { Proportion of } \\
\text { social } \\
\text { disadvantaged } \\
\text { caste }\end{array}$ & & $0.83^{* * *}$ & $0.88^{* * *}$ \\
\hline
\end{tabular}

showing the autocorrelation between iteration $\mathrm{t}$ and $\mathrm{t}-\mathrm{k}$ while the right panel is a partial auto-correlation function (PACF) showing the autocorrelation between iteration $t$ and $t-k$, having accounted for iterations $t-1$ to $\mathrm{t}-(\mathrm{k}-1)$. Here the chain looks less correlated.

\section{Discussion}

A vast body of research has provided evidence that neighborhood effect research is important for public health interventions as it reveals neighborhood level variations more clearly than individual- and household-level factors [9] [10] [31]. As it is evident from the SRS reports that IMR level is higher in the nine high-focus states of India, it is justifiable to limit the analysis to these states [1]. The objectives of this paper were to examine the effects of individual and neighborhood effect on infant mortality and further determine the extent of neighborhood variation and clustering in infant mortality. The study has considered those neighborhood level factors that mainly work as proxy for the socioeconomic status of the neighborhood, and provides plausible explanation for the variations and clustering of infant mortality at community-level in the nine high-focus states of India.

The finding of this study is consistent with similar studies suggesting significant effect of individual and neighborhood context on the risk of infant mortality. As indicated from the intra-class correlation as well as proportional change in variance (\% PCV), there is variation in infant mortality across neighborhoods as well as at the individual level. The relatively higher risk of infant mortality to the individual surrounded by disadvantaged neighborhoods suggests that neighborhoods characterized by lower SES in the context of economic position, 

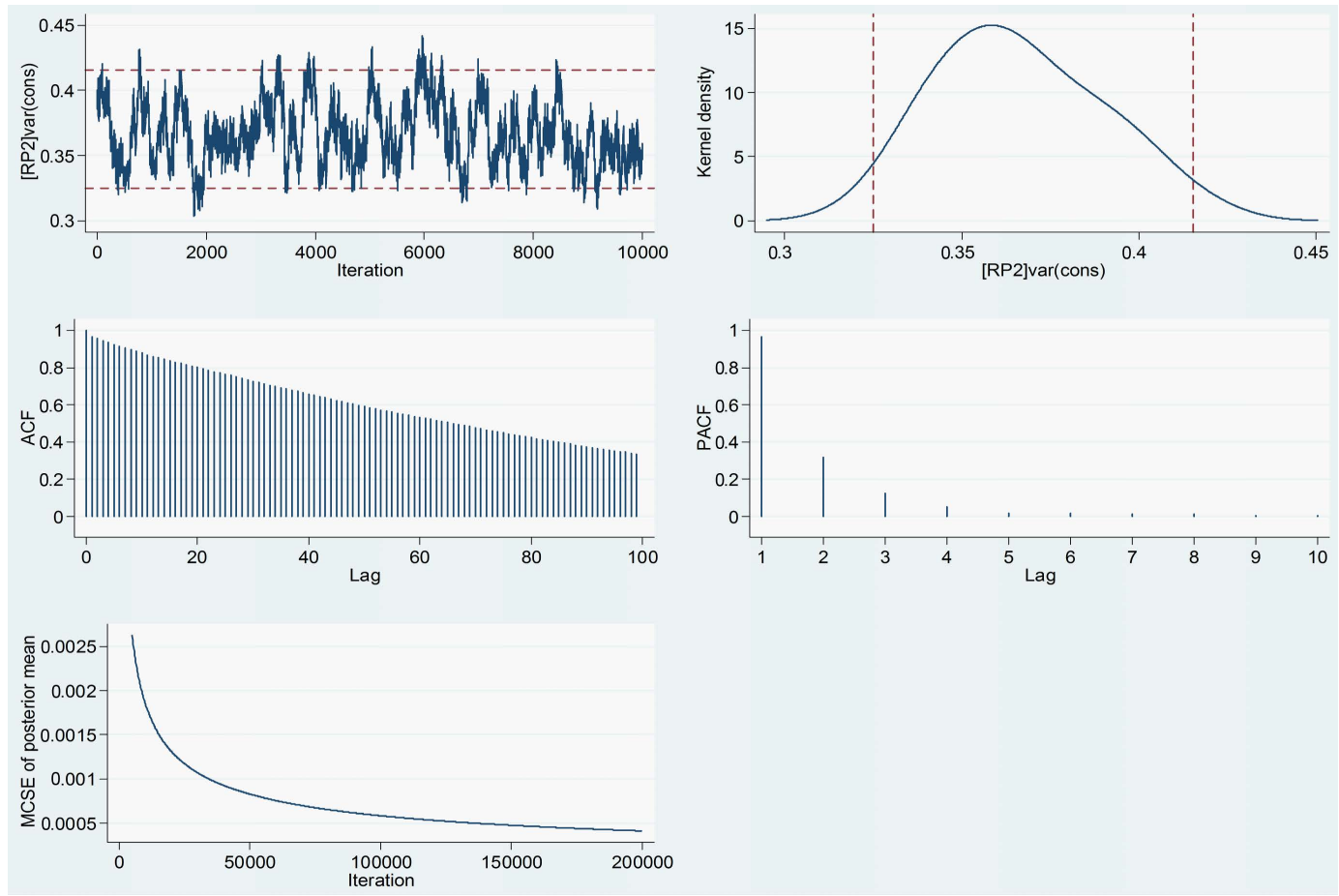

Figure 1. Five-way MCMC graphical diagnostic plots.

educational attainment of mother and higher proportion of disadvantaged groups have higher risk of infant mortality. The present analysis considers the effect of socioeconomic factors such as gender, caste, religion, household wealth, place of residence and some maternal and child level factors such as maternal schooling, maternal age at childbirth and birth order of the child on infant survival.

The importance of maternal schooling for child survival has been widely acknowledged by several researchers [32] [33]. Likewise, the finding suggested an inverse relationship between maternal schooling and infant mortality. This association, however, was attenuated after adjusting with other community and individual level factors. In most of the studies based on household surveys, household wealth indices based on information about household assets, consumer durables, quality of housing, and access to utilities and infrastructure were used as proxies to measure wealth status of the households [34] [35].

The study suggests clear evidence of the inverse association between wealth index and infant mortality. More specifically, we found that there is a wealth index gradient in the odds of infant mortality i.e., at higher quintiles of wealth index, the likelihood of infant death decreased substantially in unadjusted as well as in the multivariable model. Many studies have noted a differential in rural-urban child survival rates in developing as well as in developed countries [36] [37]. The urban mortality advantage in terms of health care facilities and infant and child mortality was observed in India [38] [39]. The finding from our analysis related to rural-urban mortality gap is in agreement with the findings of these studies. There is a slight reduction in risk of infant mortality in urban areas than in the rural ones.

In the Indian context, caste may be considered broadly as a proxy for socio-economic status and poverty. The scheduled castes and tribes, and in some cases the other backward castes are considered as socially disadvantaged groups who have a higher probability of living under adverse conditions and poverty [40]. It is evident from earlier studies based on the NFHS data that Schedule caste and Schedule tribe populations experience higher infant mortality than the other castes [39]. Consistent with these studies, we also found that the category "other caste than SC/ST" has lower mortality chances. Given the association between maternal age and infant survival, the present analysis indicates that teenage mothers are more vulnerable to experiencing infant death than the other two age groups of women (20 - $34 \& 35+)$. This study highlights that uptake of antenatal care has significant relationship with survival of the infant. Previous studies have indicated that the place of delivery is significantly related to the risk of infant death. It was found that institutional deliveries have lower chances of resulting in infant death than for babies delivered at the home. More interestingly, after accounting for commu- 
nity-level variables, the relationship between the two becomes highly significant. Considering the significance of regional diversity in influencing the variation in infant mortality in India, this study found that there is elevated risk of infant death to mothers residing in Uttar Pradesh, Chhattisgarh, Bihar and Rajasthan (Central and Eastern region).

There has been extensive assessment of role of material resources on health outcomes in cross-sectional frameworks; but studies have overlooked associating area-level income inequality with risk of infant death. Previous studies have benefited by using wealth index, constructed on the basis of assets owned by household, as a proxy for economic status of the household. Analyzing the effect of neighborhood-level wealth index on risk of infant death allows testing of the Wilkinson hypothesis [41], that societies with wider income differences show lower levels of average health than societies with greater income equality. The finding suggests that the relatively higher risk of infant mortality for individuals surrounded by disadvantaged neighborhoods characterized by poor economic status. Therefore, it can be easily hypothesized that neighborhoods in the low quintile bracket fail to provide protection in terms of increased education and, consequently, economic security and information related to health care which can be detrimental to the health of new-born and infants.

An advantage of multilevel analysis is that inclusion of wealth index and aggregated wealth score as an indicator of living standards at the household and community level respectively makes the relative wealth measures at the household and community levels more informative [42]. The final model, which includes the household wealth quintile and the average wealth quintile in the neighborhood, suggests that effect of community wealth levels is less as compared to adjusted effect of neighborhood wealth. The effect of household wealth has increased slightly when compared to the observed bivariate associations; yet, at all levels, wealth index continues to exert a considerable negative effect on infant survival.

The present study also confirms the findings of previous researches [9] [10] that there is a community-level effect of mothers' education on infant mortality in the high-focus states. There is clear evidence of education gradient in infant mortality-in communities where the level of education is generally high, odds of dying in infancy is less. An unadjusted estimate suggests that the association between neighborhoods mean level of education and infant mortality is positive and statistically significant. After adjusting with individual level as well as other community-level confounders, it was seen that neighborhood effect of education is mitigated to a certain extent. Besides, there is a positive individual-level effect if the child's mother herself is educated.

This result is consistent with Kravdal's findings in his study of education and child mortality in India (Kravdal, 2004). An interesting finding of the study is that community-level effect has significant bearing on infant mortality irrespective of whether the infant are born to less-educated mothers, providing evidence of positive externality (spillover effect) of community-level maternal education in determining infant survival.

The effect of neighborhood education may operate through a wide range of variables related to autonomy and health care [9]. Overall level of female literacy at the district level is crucial as a catalyst for trickling down of good practices in child-care, including utilization of healthcare services. The best intervention strategy for enhancement of community-level female literacy is rigorous strengthening of village-level forums such as Mahila Mandals (Women's Groups) for the welfare of women since they are involved in promoting health seeking behavior of the women in their localities.

This study also shows that high concentration of disadvantaged groups within a community is predictive of infant mortality risks, which can affect child mortality through neighborhood SES and other contextual factors. It is expected that the cultural practices, food habits and taboos prevailed in different caste groups influence the nutritional status of children which, in turn, affect the infant and child mortality [43].

In the present study, concentration of SCs/STs in the neighborhoods was constructed by aggregating the percentage of SC/ST population in the community. In previous studies, the percentage of SC/ST population was considered as an indicator of underdevelopment in community/districts/States. In some of the high-focus states, there is higher proportion of SC/ST in the total population. Therefore, it is useful to explore the effect of concentration of SC/ST in communities on health care behavior and subsequently, their infant mortality risk. However, due to the complex nature of association between SC/ST and child health it is difficult to generalize the inferences drawn from this analysis, which suggests that there is a positive and statistically significant association between higher concentration of SCs/STs and infant mortality risk.

\section{Limitation and Conclusion}

A significant limitation of this study is that it considered PSU as the neighborhood for estimating the neighbor- 
hood effect. However, analysis may be subjected to biases due to misspecification of respondent, placing them in the wrong neighborhood [44]. Moreover, all community level variables were constructed after assorting individual and household variables up to PSU level. There is likelihood of autocorrelation of individual-level variables and aggregated variables. To solve this problem, a correlation test of all the selected variables was conducted, and no two variables were found to be highly correlated. In spite of these limitations, the study provides fresh evidence that better understanding of the characteristics at both individual and community levels is crucial for addressing neighborhood clustering and variations in infant mortality. In conclusion, this study found that substantial variations in infant mortality exist across individual- and neighborhood-level factors in India. This study provides empirical evidence of the importance of both individual and neighborhood contexts in providing plausible explanations for high variations in infant mortality rates in the high-focus states. The results of this study underscore the need to look beyond the influence of individual-level factors to address clustering and variations in infant mortality in the afore-mentioned states. The study explicitly demonstrated that households surrounded by economically and socially deprived neighborhoods have elevated risks of infant mortality as compared to better-off communities and regions. The findings of this study suggest that, for attainment of child mortality-related goals, focused efforts are required to reduce infant mortality in these high-focus states. Therefore, appropriate policies promoting community-level interventions are necessary for improving infant survival rates in the economically and socially deprived neighbourhoods.

\section{References}

[1] Registrar General of India (2013) SRS Bulletin, Vol. 49, No 1. Vital Statistics Division, Office of the Registrar General of India, New Delhi.

[2] Reddy, H., Pradhan, M.R., Ghosh, R., et al. (2012) India’s Progress towards the Millennium Development Goals 4 and 5 on Infant and Maternal Mortality. WHO South-East Asia Journal of Public Health, 1, 279-289.

[3] Bhat, P.N.M. (1987) Mortality in India: Levels, Trends and Patterns. Ph.D. Dissertation, University of Pennsylvania, United States.

[4] Singh, A., Pathak, P.K., Chauhan, R.K. and Pan, W. (2011) Infant and Child Mortality in India in the Last Two Decades: A Geospatial Analysis. PLoS ONE, 6, e26856. http://dx.doi.org/10.1371/journal.pone.0026856

[5] Kumar, C., Singh, P.K. and Rai, R.K. (2012) Under-Five Mortality in High Focus States in India: A District Level Geospatial Analysis. PLoS ONE, 7, e37515. http://dx.doi.org/10.1371/journal.pone.0037515

[6] Fotso, J.C. (2009) What Does Access to Maternal Care Mean among the Urban Poor? Factors Associated with Use of Appropriate Maternal Health Services in the Slum Settlements of Nairobi, Kenya. Maternal and Child Health Journal, 13, 130-137. http://dx.doi.org/10.1007/s10995-008-0326-4

[7] Registrar General of India (2012) Annual Health Survey 2010-2011. Ministry of Home Affairs, Government of India, New Delhi. http://www.censusindia.gov.in/Common/AHSurvey.html

[8] Husain, Z. (2011) Health of the National Rural Health Mission. Economic and Political Weekly, 22, 53-60.

[9] Kravdal, O. (2004) Child Mortality in India: The Community-Level Effect of Education. Population Studies, 58, 177192. http://dx.doi.org/10.1080/0032472042000213721

[10] Ladusingh, L. and Singh, C.H. (2006) Place, Community Education, Gender and Child Mortality in North-East India. Population, Space and Place, 12, 65-76. http://dx.doi.org/10.1002/psp.393

[11] Robert, S.A. (1999) Socioeconomic Position and Health: The Independent Contribution of Community Socioeconomic Context. Annual Review of Sociology, 25, 489-516. http://dx.doi.org/10.1146/annurev.soc.25.1.489

[12] Sastry, N. (1996) Community Characteristics, Individual and Household Attributes, and Child Survival in Brazil. Demography, 33, 211-229. http://dx.doi.org/10.2307/2061873

[13] Boco, A.G. (2010) Individual and Community Level Effects on Child Mortality: An Analysis of 28 Demographic and Health Surveys in Sub-Saharan Africa. DHS Working Papers No. 73 ICF Macro, Calverton.

[14] Mosley, W.H. and Chen, L.C. (1984) An Analytical Framework for the Study of Child Survival in Developing Countries. Population and Development Review, 10, 25-45. http://dx.doi.org/10.2307/2807954

[15] Schultz, T.P. (1984) Studying the Impact of Household Economic and Community Variables on Child Mortality. Population and Development Review, 10, 215-235. http://dx.doi.org/10.2307/2807962

[16] Pickett, K.E. and Pearl, M. (2001) Multilevel Analyses of Neighborhood Socioeconomic Context and Health Outcomes: A Critical Review. Journal of Epidemiology and Community Health, 55, 111-122.

http://dx.doi.org/10.1136/jech.55.2.111 
[17] Diez, R.A.V. (2001) Investigating Neighborhood and Area Effects on Health. American Journal of Public Health, 91, 1783-1789. http://dx.doi.org/10.2105/AJPH.91.11.1783

[18] Balk, D., Pullum, T., Storeygard, A., Greenwell, F. and Neuwman, M. (2004) A Spatial Analysis of Child Mortality in West Africa. Population, Space and Place, 10, 175-216. http://dx.doi.org/10.1002/psp.328

[19] Pradhan, J. and Arokiasamy, P. (2006) High Infant and Child Mortality Rates in Orissa: An Assessment of Major Reasons. Population, Space and Place, 12, 187-200. http://dx.doi.org/10.1002/psp.408

[20] Saikia, N., Singh, A., Jasilionis, D. and Ram, F. (2013) Explaining the Rural-Urban Gap in Infant Mortality in India. Demographic Research, 29, 473-506. http://dx.doi.org/10.4054/DemRes.2013.29.18

[21] Rajaratnam, J.K., Burke, J.G. and O’campo, P. (2006) Maternal and Child Health and Neighborhood Context: The Selection and Construction of Area-Level Variables. Health \& Place, 12, 547-556. http://dx.doi.org/10.1016/j.healthplace.2005.08.008

[22] Schaefer-Mcdaniel, N., O’brien, C.M., O’campo, P. and Gearey, W. (2010) Examining Methodological Details of Neighbourhood Observations and the Relationship to Health: A Literature Review. Social Science \& Medicine, 70, 277-292. http://dx.doi.org/10.1016/j.socscimed.2009.10.018

[23] Antonovsky, A. (1967) Social Class, Life Expectancy and Overall Mortality. The Milbank Memorial Fund Quarterly, 45, 31-73. http://dx.doi.org/10.2307/3348839

[24] Auerbach, J.A. and Krimgold, B.K. (2001) Income, Socioeconomic Status and Health: Exploring the Relationship. NPA Report, National Policy Association, Washington DC.

[25] Kawachi, I. and Berkman, L.F. (2003) Neighborhoods and Health. Oxford University Press, New York. http://dx.doi.org/10.1093/acprof:oso/9780195138382.001.0001

[26] Aminzadeh, K., Denny, S., Utter, J., Milfont, T.L., Ameratunga, S., Teevale, T. and Clark, T. (2013) Neighbourhood Social Capital and Adolescent Self-Reported Wellbeing in New Zealand: A Multilevel Analysis. Social Science \& Medicine, 84, 13-21. http://dx.doi.org/10.1016/j.socscimed.2013.02.012

[27] Gilbert, N.L., Auger, N., Wilkins, R. and Kramer, M.S. (2013) Neighbourhood Income and Neonatal, Postneonatal and Sudden Infant Death Syndrome (SIDS) Mortality in Canada, 1991-2005. The Canadian Journal of Public Health, 104, e187-e192.

[28] Becares, L., Cormack, D. and Harris, R. (2013) Ethnic Density and Area Deprivation: Neighborhood Effects on Maori Health and Racial Discrimination in Aotearoa/New Zealand. Social Science \& Medicine, 88, 76-82. http://dx.doi.org/10.1016/j.socscimed.2013.04.007

[29] International Institute for Population Sciences (IIPS) (2010) District Level Household and Facility Survey, 2007-2008. IIPS, Mumbai.

[30] Leckie, G. and Charlton, C. (2013) Runmlwin-A Program to Run the MLwiN Multilevel Modelling Software from within Stata. Journal of Statistical Software, 52, 1-40.

[31] Caldwell, J.C. (1979) Education as a Factor of Mortality Decline: An Examination of Nigerian Data. Population Studies, 33, 395-413. http://dx.doi.org/10.2307/2173888

[32] Cleland, J. and van Ginneken, J.V. (1988) Maternal Education and Child Survival in Developing Countries: The Search for Pathways of Influence. Social Science and Medicine, 27, 1357-1368. http://dx.doi.org/10.1016/0277-9536(88)90201-8

[33] Filmer, D. and Pritchett, L. (1999) The Impact of Public Spending on Health: Does Money Matter? Social Science \& Medicine, 49, 1309-1323. http://dx.doi.org/10.1016/S0277-9536(99)00150-1

[34] De Poel, E.V., O’donnell, O. and van Doorslaer, E. (2009) What Explains the Rural-Urban Gap in Infant Mortality: Household or Community Characteristics? Demography, 46, 827-850. http://dx.doi.org/10.1353/dem.0.0074

[35] Bocquier, P., Madise, N.J. and Zulu, E.M. (2011) Is There an Urban Advantage in Child Survival in Sub-Saharan Africa? Evidence from 18 Countries in the 1990s. Demography, 48, 531-558. http://dx.doi.org/10.1007/s13524-011-0019-2

[36] Balarajan, Y., Selvaraj, S. and Subramanian, S.V. (2011) Health Care and Equity in India. Lancet, 377, 505-515.

[37] Subramanian, S.V., Davey, S.G. and Subramanyam, M. (2006) Indigenous Health and Socioeconomic Status in India. PLoS Medicine, 3, e421. http://dx.doi.org/10.1371/journal.pmed.0030421

[38] Adedini, S.A., Odimegwu, C., Imasiku, E.N.S., Ononokpono, D.N. and Ibisomi, L. (2015) Regional Variations in Infant and Child Mortality in Nigeria: A Multilevel Analysis. Journal of Biosocial Science, 47, 165-187.

[39] Gunasekaran, S. (2008) Determinants of Infant and Child Mortality in Rural India. Kalpaz Publications, New Delhi.

[40] Kawachi, I. and Berkman, L.F. (2003) Neighborhoods and Health. Oxford University Press, New York.

[41] Nayar, K.R. (2007) Social Exclusion, Caste \& Health: A Review Based on the Social Determinants Framework. Indian 
Journal of Medical Research, 126, 355-363.

[42] Vyas, S. and Kumaranayake, L. (2006) Constructing Socio-Economic Status Indices How to Use Principal Component Analysis. Health Policy and Planning, 21, 459-468. http://dx.doi.org/10.1093/heapol/czl029

[43] Wilkinson, R.G. (1997) Health Inequalities: Relative or Absolute Material Standards. BMJ, 314, 591-595. http://dx.doi.org/10.1136/bmj.314.7080.591

[44] Pamuk, E.R., Fuchs, R. and Lutz, W. (2011) Comparing Relative Effects of Education and Economic Resources on Infant Mortality in Developing Countries. Population and Development Review, 37, 637-664. 